\title{
RESUMO DE ARTIGO CIENTÍFICO: SUA ESTRUTURA COMPOSICIONAL
}

\section{Rildeci Medeiros}

Universidade Federal do Rio Grande do Norte

\section{RESUMO}

Este artigo reflete sobre o resumo de artigo científico e sua estrutura composicional, a partir de um relato produzido para o V Encontro Art Research Journal e II Fórum Nacional de Editores de Periódicos da área de Artes, no Instituto de Artes da UNESP, em São Paulo, em 2017. Com efeito, este artigo tem o propósito de fomentar condições para uma política editorial dos periódicos científicos e sua internacionalização, haja vista a função de divulgação e de comunicação científica desse resumo.

Palavras-chave: Resumo. Estrutura composicional. Periódicos científicos. 
Particularmente em relação ao ensino, julgamos necessário distinguir claramente entre processo de sumarização desenvolvido durante a leitura e os textos produzidos como resumos; examinar a confusão terminológica que os cerca, definindo claramente a que nos referimos ao usar o termo, discutir a possibilidade de tratá-los como gênero distinto dos demais e analisar as características do seu contexto de produção.

Anna R. Machado (2010, p. 149-150)

nicialmente, quero agradecer à comissão organizadora do Art Research Journal (ARJ) - Revista de Pesquisa em Artes - V Encontro/Il Fórum dos Editores de Periódicos da Área de Artes pelo convite para participar de um momento de discussão sobre Política Editorial e Internacionalização, em prol dos periódicos científicos e, de modo especial, sobre os resumos de artigos científicos e sua estrutura composicional.

Em seguida, ao considerarmos que a tônica de nossas reflexões, nesse evento, foi centrada na produção de resumo de artigos desses periódicos, percebemos o esforço empreendido por diversos atores e grupos sociais da área de Artes, pelo trabalho articulado entre professores, pesquisadores, universidade, editores, associações e bibliotecários.

Sendo assim, este artigo tem o propósito de fomentar condições de editoração de periódicos científicos, que incluem atribuição de palavras-chave e produção de resumo, tendo em vista a sua internacionalização.

A partir da criação da $A R J$, em novembro de 2012, foram envidados muitos esforços no que se refere ao aprimoramento das condições da política editorial dessa revista. Primeiro, isso ocorreu pela necessidade que emergiu de um refinamento de suas condições de editoração e sua consolidação, uma vez que ela tem como foco promover a produção, a divulgação e a circulação de pesquisas e dos periódicos dessa área do conhecimento, tanto no país como a sua inserção internacional junto à comunidade cientifica. Segundo, após a publicação de sete números dessa revista, tornou-se evidente a necessidade de se rever e de se aprimorar, cada vez mais, critérios referentes à editoração científica, por exemplo, os termos de indexação em Artes - palavras-chave e/ou descritores - e, ainda, os resumos. Isto se justifica em função da relevância desses produtos documentários, como instrumentos essenciais para a representação do conteúdo informacional do texto-fonte, principalmente nos processos de circulação e de recuperação da informação.

No que se refere a esse resumo, enquanto uma das modalidades típicas de produtos da Análise Documentária (Kobashi, 1996, 2007), ele torna-se essencial para a divulgação e a comunicação científica, uma vez que essa é sua função precípua, enquanto gênero concernente à produção de gêneros acadêmicos

Nessa perspectiva, a abordagem ora apresentada sobre o resumo de artigo científico, no $A R J$ 2017, partiu de questões pertinentes a esse gênero discursivo-textual, na modalidade escrita e em língua portuguesa (Medeiros, 2015). 
Com efeito, apresentamos, de forma breve, noções subjacentes que contemplam o tema tópico - resumo - e sua estrutura composicional. Daí, partimos de abordagens distintas de estudos levantados para ampliarmos a noção sobre esse gênero, bem como sobre sua organização textual.

O conceito "resumo documentário" é tomado, nesta comunicação, com a acepção de que esse gênero é uma modalidade de representação condensada do conteúdo informacional do texto original para promover a circulação da informação e, por consequência, a obtenção da informação desejada (Kobashi, 1997). Para isso, o resumo deve ser portador de um significado tal que venha a garantir a equivalência de sentido com o texto representado no processo de comunicação técnico-científica. Assim, compreendemos que o resumo, para exercer sua função efetiva de promover a comunicação científica, deve adotar princípios de organização textual que representem o conteúdo do texto base (Medeiros, 2015; Kryzanowski; Ferreira; Medeiros, 2005).

Além disso, as convenções e os padrões normativos pautados pelas normas aplicadas à informação e à documentação, referentes à elaboração e à apresentação de resumo, sobretudo a NBR 6028/2003, têm sido um dos aspectos exigidos por eventos acadêmicos e revistas científicas.

Assim sendo, essa reflexão configurou-se a partir da noção de estrutura composicional (sequências e planos de textos) como um dos níveis ou planos da análise textual, conforme construtos teóricos empreendidos por Jean-Michel Adam (2011). Então, para compreendermos como se dá a estrutura composicional do resumo de artigos científicos, devemos ter em vista as categorias informacionais relevantes do texto original para a organização global dessa categoria de texto. Então, ao focalizarmos o plano de texto como um princípio organizador da leitura, isso permitirá o desenvolvimento da textualidade, uma vez que esse plano é responsável pela estrutura composicional do texto (Adam, 2011).

Salientamos que determinadas categorias informacionais da composição textual do resumo são necessárias para o processo de representação do texto-fonte e sua produção de sentido. Para tanto, estas reflexões têm como base teórica e metodológica a Linguística Textual (LT) (Koch, 2006; Marcuschi, 2009) e, sobretudo, a Análise Textual dos Discursos (ATD) (Adam, 2011, 2012), uma vez que buscamos compreender a estrutura organizacional do resumo tanto do ponto de vista linguístico como textual.

Nessa perspectiva, um modelo de análise textual proposto por Kobashi (1994), para a elaboração de resumos, apresenta aspectos, tais como: a seleção das ideias representativas do conteúdo informacional e a combinação destas. Sua metodologia está fincada no princípio elementar de que a seleção de informações relevantes deve ser antecipada pela operação de identificação e hierarquização de informações textuais, com base na estrutura composicional do texto.

A propósito do processo de redação desse resumo, a autora chama a atenção para se identificar a superestrutura do texto numa primeira leitura. Ressalta que "[...] a atenção deverá concentrar-se nas categorias pertinentes ao tipo de resumo a ser produzido" (Kobashi, 1994, p. 178). E, ainda, ao se reportar ao resumo informativo, afirma que, nesse caso, 
“[...] a leitura procurará contemplar todas as categorias da superestrutura; já no caso do resumo indicativo, o leitor deverá deter-se apenas nos segmentos textuais pertinentes para esse tipo de informação documentária" (Kobashi, 1994, p. 178); pois, de acordo com esse gênero e o campo do conhecimento, o(a) autor(a)/produtor(a) do resumo o elabora conforme a natureza do trabalho acadêmico. Assim, ela caracteriza a elaboração do resumo como um processo que consiste em: identificação do tema do texto, identificação das informações textuais, seleção das informações mais relevantes e representação da informação, sendo que as três primeiras são operações de seleção e a última de combinação. Para a autora, a primeira operação consiste em identificar o tema, uma vez que esse "é responsável pela condensação semântica do texto ao seu nível hierárquico mais geral, sem a qual, a compreensão do texto fica prejudicada". Outra operação é a identificação da informação, a partir do reconhecimento da superestrutura textual (Kobashi, 1994, p. 177).

De modo sintético, ilustramos as categorias informacionais de base que constituem a metodologia de indexação e de produção de resumos, com base no modelo proposto por Kobashi (1994), a partir de três variantes de textos pesquisados. Isso se fez com base na estrutura composicional dos textos com um modelo específico de coleta de dados. Para o resumo, essas categorias são definidas como essenciais ou facultativas, conforme a área do conhecimento (Quadros 1, 2 e 3). Embora nosso foco de reflexão seja o resumo, os "esquemas" a seguir apresentam as categorias que o constituem juntamente com a da indexação. Observamos nesses esquemas que determinadas categorias informacionais do resumo são integradas em blocos e de acordo com os textos utilizados.

\section{Quadro 1. Resumo de texto tipo 1}

\begin{tabular}{|c|c|c|c|}
\hline TEXTO TIPO 1 & INFORMATIVO & INDICATIVO & INDEXAÇÃO \\
\hline TEMA & 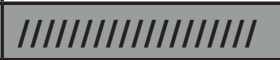 & $|I| I|I| I|I| I|I| I|I| I||$ & $|/| I|||||||||||||||||||| \mid$ \\
\hline PROBLEMA & $|/| I / I / I / I / I / I / I / I / I$ & IIIIIIIIIIIIIIIIIIII & \\
\hline HIPÓTESES & 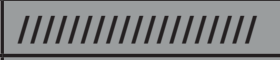 & & \\
\hline METODOLOGIA & 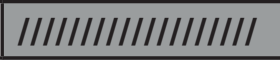 & & \\
\hline RESULTADOS & 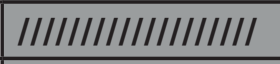 & & \\
\hline CONCLUSÃO & 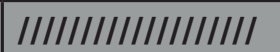 & $\mid / I / I / I / I / I / I / I / I / I)$ & \\
\hline
\end{tabular}

Fonte: Kobashi (1994, p. 178)

Quadro 2. Resumo do texto tipo 2

\begin{tabular}{|c|c|c|c|}
\hline TEXTO TIPO 2 & INFORMATIVO & INDICATIVO & INDEXAÇÃO \\
\hline TEMA & 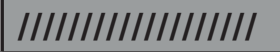 & IIIIIIIIIIIIIIIIIII & I/I/I/I/I/I/I/I/I/I \\
\hline TESE & 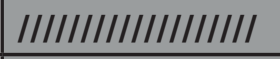 & $\mid / I / I / I / I / I / I / I / I / I I$ & \\
\hline ARGUMENTOS & $|/| I||||||||||||||||||||$ & & \\
\hline CONCLUSÃO & 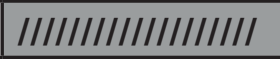 & $\mid / I / I / I / I / I / I / I / I / I$ & \\
\hline
\end{tabular}

Fonte: Kobashi (1994, p. 179) 


\section{Quadro 3. Resumo de texto tipo 3}

\begin{tabular}{|c|c|c|c|}
\hline TEXTO TIPO 2 & INFORMATIVO & INDICATIVO & INDEXAÇÃO \\
\hline TEMA & 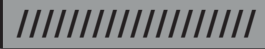 & |IIIIIIIIIIIIIIIIIII & IIIIIIIIIIIIIIIIIII \\
\hline PROBLEMA & /IIIIIIIIIIIIIIIIIIIII & $|/| /|||||||||||||||||| \mid$ & \\
\hline CAUSAS & 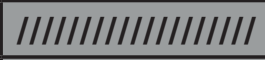 & & \\
\hline SOLUÇÃO & I/I/I/I/I/I/I/I/I/II & $\mid / / / / / I / I / / I / I / I / I$ & \\
\hline
\end{tabular}

Além disso, torna-se necessário adotar alguns procedimentos para o processo de fragmentação do texto-fonte, já que descrever e interpretar suas unidades textuais são fundamentais para a compreensão da estrutura composicional dos resumos.

Tal procedimento se dá a partir da leitura de cada texto, e, por consequência, a marcação de diferentes unidades textuais, como categorias de análise para compor a estrutura global do resumo. Essas unidades de texto podem ser descritas desde a que se refere à unidade textual de primeira ordem - isto é, a proposição-enunciado - até as unidades de complexidade crescente - quer dizer, as sequências e, ainda, os planos de textos. Assim, no caso específico da configuração dos planos de textos, deve-se observar na análise textual a superestrutura do texto, para que a mesma seja representada por meio do resumo. De modo geral, isso se dá pelos segmentos textuais que comportam, sobretudo, dois momentos-chave da estrutura composicional, ou seja, a abertura e o fechamento-conclusão. A identificação dessas e de outras categorias informacionais, em que se toma a proposição-enunciado como unidade textual de base para as operações de textualização, torna-se essencial para podermos caracterizar as sequências textuais e os planos de textos do gênero em estudo.

Assim sendo, recomendamos algumas instruções básicas para a produção do resumo documentário, tais como:

- Identificar o tema e apresentá-lo na abertura do texto;

- Marcar e extrair do texto-fonte as outras ideias principais, por exemplo, a metodologia, os resultados e a conclusão, conforme a área do conhecimento;

- Manter aspectos essenciais, tais como: objetividade, clareza, coesão e coerência;

- Evitar fazer transcrição do texto representado;

- Não fazer uma mera redução de parágrafos, por meio de fragmentos textuais, do texto original;

- Seguir os padrões estabelecidos pela NBR 6028/2003, no que se refere à sua extensão textual. 


\section{Considerações finais}

A partir dessas reflexões, depreendemos que os processos de organização da informação e do conhecimento, para fins de recuperação, requerem maior atenção da comunidade técnico-científica, no que se refere aos processos de produção de resumo e de indexação. Diante disso, emerge a necessidade de um maior aparato teórico para esse processo produtivo, bem como um rigor metodológico que venha garantir a qualidade dos termos de indexação e dos resumos publicados tanto na Revista ARJ como em outros periódicos da área de Artes.

Ressaltamos que, para a produção do resumo, as categorias informacionais devem ser definidas como essenciais ou facultativas, conforme a natureza do gênero textual e a área do conhecimento.

$\mathrm{Na}$ atualidade, o resumo, em sua função efetiva de promover a comunicação científica, é visto como um dos gêneros mais representativos da produção acadêmico-científica, diante da diversidade de gêneros acadêmicos e do seu propósito informacional.

Portanto, acredita-se que, com o aprimoramento dos critérios referentes à preparação de revistas científicas, sua editoração para esses periódicos contribuirá para uma política editorial em consonância com a internacionalização dos mesmos.

\section{Referências}

ADAM, Jean-Michel. Análise textuel des discours: niveaux ou plans d'analyse. Filologia e linguística portuguesa, São Paulo, v. 14, n. 2, p. 190-201, 2012.

ADAM, Jean-Michel. A linguística textual: introdução à análise textual dos discursos. Tradução de Maria das Graças Soares Rodrigues; João Gomes da Silva Neto; Luis Passeggi; Eulália Vera Lúcia Fraga Leurquin. Revisão científica de João Gomes da Silva Neto; Luis Passeggi. 2. ed. rev. e aum. São Paulo: Cortez, 2011. Tradução de: La linguistique textuelle: introduction à l'analyse textuelle des discours.

ASSOCIAÇÃO BRASILEIRA DE NORMAS TÉCNICAS. NBR 6028: informação e documentação: resumo - apresentação. Rio de Janeiro, 2003.

KOBASHI, Nair Yumiko. Análise documentária e representação da informação. Revista Informare, Rio de Janeiro, v. 2, n. 2, p. 5-27, 1996.

KOBASHI, Nair Yumiko. A elaboração de informações documentárias: em busca de uma metodologia. 1994. Tese (Doutorado em Ciências da Comunicação). Escola de Comunicação e Artes, Universidade de São Paulo, São Paulo, 1994. 
KOBASHI, Nair Yumiko. Fundamentos semânticos e pragmáticos da construção de instrumentos de representação de informação. DataGramaZero - Revista de Ciência da Informação, v. 8, n. 6, dez. 2007. Disponível em: http://www.dgz.org.br/dez07/ Art_01.htm. Acesso em: 20 out. 2011.

KOBASHI, Nair Yumiko. Resumos documentários: uma proposta metodológica. Revista de Biblioteconomia de Brasília, v. 21, n. 2, p. 201-210, jul./dez. 1997.

$\mathrm{KOCH}$, Ingedore G. Villaça. Introdução à linguística textual: trajetória e grandes temas. 2. tiragem. São Paulo: Martins Fontes, 2006.

KRYZANOWSKI, Rosaly Fávero; FERREIRA, Maria Cecília G.; MEDEIROS, Rildeci. Instrumental aos autores para preparação de trabalhos científicos. In: FERREIRA, Sueli Mara S. P.; TARGINO, Maria das Graças (Org.). Preparação de revistas científicas: teoria e prática. São Paulo: Reichmann \& Autores, 2005. cap. 2, p. 55-72.

MACHADO, Anna R. Revisitando o conceito de resumos. In: DIONISIO, Angela P.; MACHADO, Anna R.; BEZERRA, Maria A. (Org.). Gêneros textuais \& ensino. São Paulo: Parábola, 2010. pt. 2, cap. 2, p. 149-162.

MARCUSCHI, Luiz A. Gêneros textuais: definição e funcionalidade. In: DIONÍSIO, Ângela P.; MACHADO, Anna R.; BEZERRA, Maria A. (Org.). Gêneros textuais \& ensino. São Paulo: Parábola, 2010. pt. 1, cap. 1, p. 19-38.

MARCUSCHI, Luiz A. Linguística de texto: o que é e como se faz? Ed. espec. Recife: Ed. Universitária UFPE, 2009. (Original 1983 e reimpressão 2005).

MEDEIROS, Rildeci. Resumo de dissertações e teses: a estrutura composicional à luz da análise textual dos discursos. 2015. Tese (Doutorado em Estudos da Linguagem). Centro de Ciências Humanas, Letras e Artes, Universidade Federal do Rio Grande do Norte, Natal, 2015. 